\title{
US puts global collaboration at heart of AlDS effort
}

\section{Rex Dalton, San Diego}

The US National Institutes of Health (NIH) has announced a global strategy for fighting AIDS that will place more emphasis on international research and scientific training.

Coordinated by the NIH's Office of AIDS Research (OAR), officials say that the plan is expected to be the basis for greater US involvement in international collaborations.

The NIH spent about $\$ 90$ million last year on international AIDS research, with that amount expected to increase to $\$ 100$ million when Congress approves the delayed 2001 federal budget (see page 627).

Officials cannot yet discuss their funding plans for the initiative in 2002, but say that the growing concern in the United States about the international impact of AIDS should lead to "significant increases".

"A strong, coordinated biomedical research effort is critical to address the global pandemic," says Jack Whitescarver, OAR's acting director.

The strategic plan is expected to

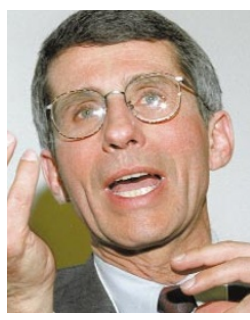

NIH's Anthony Fauci backs international AIDS research. encourage training for international scientists to take part in $\mathrm{NIH}$ studies, research workshops, scholarships for international scientists, prevention strategies and new approaches to research funding.

The NIH developed the plan with a panel of outside academics, and released it on 1 December to mark World AIDS Day. "It is our sincere hope that the fruits of this research will help to alleviate the suffering caused by HIV and AIDS throughout the world," said Anthony Fauci, director of the National Institute of Allergy and Infectious Diseases.

Advocacy groups for AIDS research reacted cautiously to the announcement, noting that it is largely a repackaging of existing programmes. One said that he did not want to comment publicly on the plan, as the NIH was trying to heighten awareness of international issues and it was too early to tell whether the initiative would lead to substantial change.

Officials at another advocacy organization, the New York-based Treatment Action Group (TAG), said that the plan may plug gaps in research. For instance, says TAG's Mark Harrington, the United States now spends about $\$ 50$ million a year on research related to US children with AIDS, but there are only a few such cases. Globally, he points out, paediatric AIDs is a huge problem, but the United States probably spends less than $\$ 5$ million each year researching it.

In the early 1980s, the US government began international AIDS research projects in Haiti and Zaire. It then expanded AIDS research projects to 50 countries in Africa, Asia, Europe and Latin America.

Officials say that the new plan will help researchers to build new collaborations. The $\mathrm{NIH}$ will form a Global Strategy Group to track the plan's implementation.

nih.gov/od/oar

\section{Scientists win vote of confidence from French public}

\section{Declan Butler, Paris}

People in France still see science in a positive light despite the recent tempests over mad cow disease, HIV in blood, and genetically engineered food, according to a survey undertaken for the research ministry.

Of 1,000 adults surveyed by the polling organization Taylor Nelson Sofres, $\mathbf{5 3} \%$ said they most trusted scientists to control the progress and ethical use of science - far ahead of intellectuals and philosophers (19\%), associations and trade unions $(9 \%)$, or religious groups $(6 \%)$. Politicians were most trusted by only $4 \%$.

Roger-Gérard Schwartzenberg, the minister for research, said the results showed an urgent need to incorporate science more effectively into decisionmaking. There should be more debate of contemporary scientific issues, he said, and political parties and presidential candidates should increase the discussion of science in their manifestos.

When respondents were asked to choose priority areas, medical research came out on top, with $84 \%$ of the vote, followed by environmental science at $54 \%$ and energy research at $32 \%$.

Nine-tenths of those polled said research should be a priority for France, and two-thirds that the research budget should be increased; only $3 \%$ thought it should be reduced. A career in science was regarded as attractive by $84 \%$.

\section{Mars images may be legacy of lakeside view}

\section{Tony Reichhardt, Washington}

NASA seems to have trouble keeping secrets, when it comes to Mars.

Four years ago, it was claims of fossil life in a Martian rock that set the media in a spin, after word leaked out ahead of publication in the journal Science.

Now, in an uncanny echo of these events, a NASA press conference originally planned for Thursday 7 December was hastily pulled forward to the Monday after news services ran the story that scientists Michael Malin and Ken Edgett of Malin Space Science Systems in San Diego had found evidence for ancient lakes on Mars.

Malin and Edgett report in the 8 December issue of Science on layered outcrops that appear to be sedimentary rocks in several natural basins. The outcrops, which are between 4.3 billion and 3.5 billion years old, are possible evidence that surface water was widespread in the planet's distant past.

The researchers caution that water may not be the only explanation for the images returned by NASA's Mars Global Surveyor. It is also possible, for example, that atmospheric pressure was once higher on Mars than it is today, causing winds to spread dust around the surface.

Layered deposits were discovered on Mars in the 1970s, but have never been seen in so much detail. The lake sediments if the evidence holds up - would have important implications for any future fossil hunts. "These discoveries give us some direction on where to go," said Jim Garvin, NA\&A' 2poogracmitian ntaigaztines fidr Mars exploration.

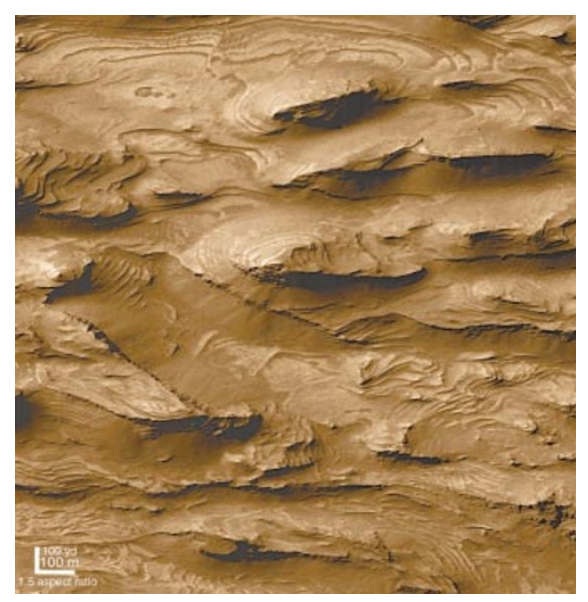

Splash down? These layered patterns on the surface of Mars could have been caused by water. 